\title{
Blockade of IL-6 signaling exacerbates liver injury and suppresses antiapoptotic gene expression in methionine choline-deficient diet-Fed db/db mice
}

\author{
Kanji Yamaguchi ${ }^{1}$, Yoshito Itoh ${ }^{1}$, Chihiro Yokomizo ${ }^{1}$, Takeshi Nishimura ${ }^{1}$, Toshihisa Niimi ${ }^{1}$, Atsushi Umemura ${ }^{1}$, \\ Hideki Fujii ${ }^{1}$, Takeshi Okanoue ${ }^{1,2}$ and Toshikazu Yoshikawa ${ }^{1}$
}

Our previous study revealed that blockade of interleukin-6 (IL-6)-STAT3 signaling ameliorated liver injury, although hepatic STAT3 ${ }^{-/-}$or GP130 13 mice have been reported to develop severe liver injury, in a murine methionine choline deficient (MCD) diet-induced model of non-alcoholic steatohepatitis (NASH). In this study, to determine whether profound blockade of IL-6-STAT3 signaling may still ameliorate liver injury, we studied $\mathrm{db} / \mathrm{db}$ mice, which have impaired leptin-mediated STAT3 activation, using the MCD diet-induced NASH model. Male lean and db/db mice (6 weeks old) were fed either control chow or an MCD diet for 8 or 12 weeks. Half of the mice were treated with $15 \mathrm{mg} / \mathrm{kg}$ rat anti-mouse IL-6 receptor neutralizing antibody (MR16-1) intraperitoneally twice weekly, the remainder were injected with $15 \mathrm{mg} / \mathrm{kg}$ rat $\mathrm{lgG}$ as a control. Hepatic steatosis, injury, fibrosis, markers of lipid peroxidation/oxidant stress and antiapoptotic gene expression were evaluated. Plasma IL-6 levels were elevated in all groups of $\mathrm{db} / \mathrm{db}$ mice. Although hepatic IL-6/ GP130 signaling was activated in chow-fed db/db mice, this was suppressed in MCD diet-fed db/db mice, accompanied by downregulation of hepatic IL-6 receptor and GP130 mRNA expression. MR16-1 treatment of MCD dietfed $\mathrm{db} / \mathrm{db}$ mice further repressed STAT3 activities and expression of STAT3-related antiapoptotic genes, such as Bcl-2 and Ref-1, but increased plasma-free fatty acid and hepatic markers of lipid peroxidation/oxidant stress, leading to increased liver injury, hepatocyte apoptosis and liver fibrosis. Although 'moderate' blockade of enhanced IL-6-STAT3 signaling may be beneficial in NASH, as we reported previously, these findings demonstrate that a profound defect in STAT3 activation is detrimental in terms of liver injury, hepatocyte apoptosis and liver fibrosis, indicating the hepato-protective role of IL-6 signaling in this severe NASH model.

Laboratory Investigation (2011) 91, 609-618; doi:10.1038/labinvest.2011.2; published online 14 February 2011

KEYWORDS: NASH; IL-6; IL-6 receptor; STAT3; MCD diet; db/db mice

Non-alcoholic fatty liver disease (NAFLD) is one of the most common liver diseases worldwide. ${ }^{1}$ The pro-inflammatory cytokines, tumor necrosis factor-alpha (TNF- $\alpha)$ and interleukin-6 (IL-6) are considered to have a critical role in the progression of NAFLD to more advanced stages of liver damage. Although evidence is accumulating that reinforces the idea that TNF- $\alpha$ has an important role in the development of non-alcoholic steatohepatitis (NASH), the role of IL-6 in NASH remains obscure. ${ }^{2,3}$ The latest publications reported that hepatic IL-6 expression correlates positively with the plasma IL-6 levels and the degree of hepatic inflammation, stage of hepatic fibrosis and systemic insulin resistance. ${ }^{2-4}$
These findings suggest an important role for IL-6 as in the development of human NASH.

On the contrary, IL-6 is well known as a hepato-protective cytokine. ${ }^{5,6}$ IL-6 exerts an effect directly on hepatocytes and induces the translocation of STAT3 to the nuclei, causing early gene activation and mitosis. ${ }^{7,8}$ This signaling not only exerts an effect on hepatocyte proliferation, but also protects the liver against various forms of injury, such as ischemia and reperfusion, toxins, alcohol and death-mediated Fas activation..$^{9-11}$ Mice that are deficient in IL-6 have an impaired ability to regenerate their livers after partial hepatectomy and also show reduced hepatic expression of the

\footnotetext{
${ }^{1}$ Molecular Gastroenterology and Hepatology, Graduate School of Medical Science, Kyoto Prefectural University of Medicine, Kyoto, Japan and ${ }^{2}$ Center of Gastroenterology \& Hepatology, Saiseikai Suita Hospital, Osaka, Japan

Correspondence: Dr Y Itoh, MD, PhD, Molecular Gastroenterology and Hepatology, Graduate School of Medical Science, Kyoto Prefectural University of Medicine, 465 Kaji-cho, Kawaramachi-Hirokoji, Kamigyou-ku, Kyoto 602-8566, Japan.

E-mail: yitoh@koto.kpu-m.ac.jp

Received 8 July 2010; revised 18 November 2010; accepted 13 December 2010
} 
antiapoptotic mediators Bcl-2, Bcl-xL and Ref-1 (see ref. 5, $10-12)$.

$\mathrm{Db} / \mathrm{db}$ mice develop obesity, severe type 2 diabetes and fatty liver spontaneously because of a functional defect in the long-form of the leptin receptor (Ob-Rb), which seems to be the dominant signaling molecule to the receptor for the phosphorylation of STAT3 and has a key role in the regulation of food intake, insulin sensitivity and the control of body weight. ${ }^{13}$ Feeding $\mathrm{db} / \mathrm{db}$ mice with an MCD diet induces steatohepatitis and liver fibrosis within only 8 weeks, providing a useful small animal model for progressive, obesityrelated NASH. ${ }^{14-16}$

We have reported recently that blockade of IL-6 signaling by neutralizing antibody against the IL-6 receptor (MR16-1), which is a specific antagonist of the mouse IL- 6 receptor, enhanced liver steatosis but improved liver injury in wildtype lean mice fed with an MCD diet. ${ }^{17,18}$ We interpreted this result as indicating that excess IL- 6 produced by an MCD diet may have exerted an effect as a pro-inflammatory cytokine, leading to the progression of NASH. Therefore, blockade of excessive IL-6-mediated signaling improved liver injury in a lean mouse fed with an MCD diet. In this study, to determine whether or not profound blockade of IL-6-STAT3 signaling may still ameliorate liver injury, we studied $\mathrm{db} / \mathrm{db}$ mice, which have impaired leptin-mediated STAT3 activation, using the MCD diet-induced NASH model.

\section{MATERIALS AND METHODS}

\section{Animals and Treatments}

A mouse model of MCD diet-induced NASH was studied. Male C57/BL6 (lean) mice (6 weeks old) and db/db (BKS.Cg$\left.\mathrm{m}+/+\operatorname{Lepr}^{\mathrm{db}} / \mathrm{J}\right)$ mice were purchased from Japan Jackson Laboratories, maintained in a temperature- and light-controlled facility, and permitted consumption of water ad libitum. A total of 20 lean and $\mathrm{db} / \mathrm{db}$ mice were fed a control chow diet (cat no. 960441; ICN, Aurora, OH, $n=10$ ) or an MCD diet (cat no. 960439; ICN, $n=10$ ) for 8 weeks. Another $10 \mathrm{db} / \mathrm{db}$ mice were fed an MCD diet for 12 weeks. Half of the chow and MCD diet-fed mice were treated with $15 \mathrm{mg} / \mathrm{kg}$ rat anti-mouse IL-6 receptor antibody (MR16-1; Cyugai Pharmaceutical, Tokyo, Japan) intraperitoneally twice weekly for 8 or 12 weeks, the remainder were injected with control rat IgG (Equitech-Bio, Kerrville, TX, USA). ${ }^{17-19}$ All mice were killed 2 days after the final injection of MR16-1. All animal experiments fulfilled the requirements for humane animal care in Kyoto Prefectural University of Medicine.

\section{Immunoblot Assay}

Nuclear proteins isolated using a NE-PER Nuclear Extraction Reagent Kit (PIERCE Biotechnology, Rockford, IL, USA), and proteins isolated from whole livers were electrophoresed in SDS-PAGE gels and transferred to PVDF membranes. Membranes were probed with anti-STAT3, anti-phosphoSTAT3, anti-Histone H3 (Cell signaling Technology, Beverly, MA, USA), anti-Bcl-2 (NeoMarker, Fremont, CA, USA),
anti-SOCS3, anti- $\alpha$-actin (Santa-Cruz) or anti-Ref-1 (BD transduction Lab., Lexington, KY, USA) antibody, followed by horseradish peroxidase (HRP)-conjugated anti-mouse or rabbit IgG (Amersham, UK). Antigens were visualized by ECL (Amersham). The immunoblots were scanned and band intensities were quantified by Image J (NIH) densitometry analysis.

\section{Two-Step Real-Time RT-PCR}

Real-time PCR was performed as described. ${ }^{20}$ Specificity was confirmed for all primer pairs (Table 1) by sequencing the PCR products. We performed a validation experiment to demonstrate that the amplification efficiencies of the target and reference were approximately equal, as reported in Applied Biosystems User Bulletin No. 2. We confirmed the absolute values of the slope of log input amount $v s \Delta \mathrm{CT}$ were $<0.1$. Target gene levels are presented as a ratio of levels in treated versus corresponding control groups, according to the $\Delta \Delta \mathrm{Ct}$ method as reported. ${ }^{21,22}$

Table 1 RT-PCR primers for analysis

\begin{tabular}{|c|c|c|}
\hline Genes & Direction & Sequences \\
\hline \multirow[t]{2}{*}{ Gus } & Forward & 5'-GCAGTTGTGTGGGTGAATGG-3' \\
\hline & Reverse & 5'-GGGTCAGTGTGTTGTTGATGG-3' \\
\hline \multirow[t]{2}{*}{ SOCS3 } & Forward & $5^{\prime}$-GGGTGGCAAAGAAAAGGAG-3' \\
\hline & Reverse & 5'-GTTGAGCGTCAAGACCCAGT-3' \\
\hline \multirow[t]{2}{*}{ IL-6 R $\alpha$} & Forward & $5^{\prime}$-CATCTGTGAGTGGCGTCCGA-3' \\
\hline & Reverse & 5'-AACGCTTCGTTGTGGCTGGA-3' \\
\hline \multirow[t]{2}{*}{ GP130 } & Forward & 5'-AGCATCTCCAGCAACGAGGAG-3' \\
\hline & Reverse & 5'-GGACAGGCTTCAGGCTGACT-3' \\
\hline \multirow[t]{2}{*}{$T N F-\alpha$} & Forward & 5'-TCGTAGCAAACCACCAAGTG-3' \\
\hline & Reverse & 5'-AGATAGCAAATCGGCTGACG-3' \\
\hline \multirow[t]{2}{*}{$T G F \beta-1$} & Forward & 5'-TTGCCCTCTACAACCAACACAA-3' \\
\hline & Reverse & 5'-GGCTTGCGACCCACGTAGTA-3' \\
\hline \multirow[t]{2}{*}{ Pro Colla1 } & Forward & 5'-GACATCCCTGAAGTCAGCTGC-3' \\
\hline & Reverse & $5^{\prime}-\mathrm{TCCCTTGGGTCCCTCGAC-3^{ \prime }}$ \\
\hline \multirow[t]{2}{*}{$\alpha-S M A$} & Forward & 5'-ACTGGGACGACATGGAAAAG-3' \\
\hline & Reverse & $5^{\prime}$-AGAGGCATAGAGGGACAGCA-3' \\
\hline \multirow[t]{2}{*}{ TIMP-1 } & Forward & 5'-CATGGAAAGCCTCTGTGGATATG-3' \\
\hline & Reverse & 5'-GATTGTGCAAATTCCGTTCCTT-3' \\
\hline \multirow[t]{2}{*}{ FATP1 } & Forward & 5'-CGCTITCTGCGTATCGTCTG-3' \\
\hline & Reverse & 5'-GATGCACGGGATCGTGTCT-3' \\
\hline \multirow[t]{2}{*}{ FATP2 } & Forward & 5'-GGTATGGGACAGGCCTTGCT-3' \\
\hline & Reverse & 5'-GGGCATTGTGGTATAGATGACATC-3' \\
\hline \multirow[t]{2}{*}{ FATP5 } & Forward & 5'-CTACGCTGGCTGCATATAGATG-3' \\
\hline & Reverse & 5'-CCACAAAGGTCTCTGGAGGAT-3' \\
\hline
\end{tabular}




\section{Immunohistochemistry and Analysis of Liver Architecture}

Serial sections were stained with H\&E using standard techniques. After deparaffinization, microwave antigen retrieval and blocking of endogenous peroxidase activity, other sections were incubated with a TdT-mediated dUTP-digoxigenin nick end labeling (TUNEL) reaction mixture, containing terminal deoxyribonucleotidyl transferase (TdT) and fluorescein-dUTP (Roche Diagnostic, Indianapolis, IN, USA), anti- 4-hydroxy-2-nonenal (HNE) (HNEJ-2; Nikken, Shizuoka, Japan) or anti- $\alpha$-smooth muscle actin (SMA) (DakoCytomation, Carpinteria, CA, USA) antibody. Antigen was demonstrated using secondary anti-mouse polymer HRP and DAB chromagen (Dako) and counterstaining with Gill's hematoxylin. TUNEL-positive hepatocytes were counted in three randomly selected fields/section ( $\times 100$ magnification).

\section{Quantification of Hepatic Collagen Content}

Liver sections were stained with picrosirius red and counterstained with fast green (Sigma-Aldrich Japan). Sirius red staining was quantitated by Image $\mathrm{J}$ software in three randomly selected fields/section ( $\times 200$ magnification).

\section{Tissue and Plasma Biochemical Measurements}

Plasma aspartate aminotransferase (AST), alanine aminotransferase (ALT), Free Fatty Acid (FFA), total cholesterol (T-CHO) and triglyceride levels were measured as described previously. $^{20}$ Concentrations of plasma IL-6, plasma serum amyloid A (SAA), tissue triglyceride and tissue thiobarbituric acid-reactive substances (TBARS) were measured by IL-6 Mouse ELISA Kit (R\&D Systems, Minneapolis, MN, USA), SAA Mouse ELISA Kit (Streassgen, Victoria, Canada), Triglyceride Detection Kit (Sigma-Aldrich) and TBARS Assay kit (Cayman Chemical, Ann Arbor, MI, USA) according to the manufacturers' instructions.

\section{Statistical Analysis}

Results are expressed as mean \pm s.e.m. Significance was established using the Student's $t$-test and analysis of variance
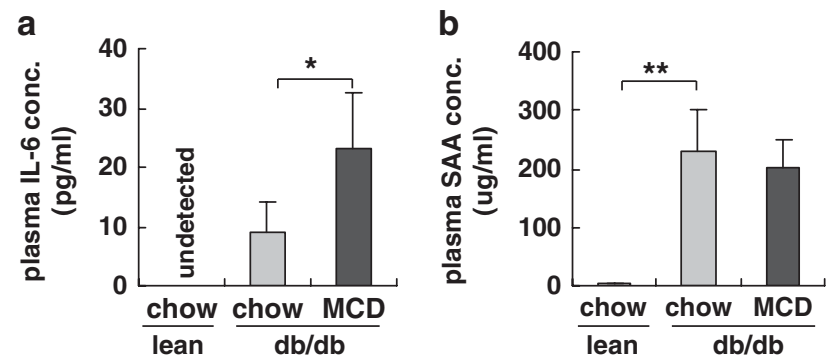

Figure 1 Plasma interleukin-6 (IL-6) levels in lean and db/db mice. (a) Plasma IL-6 levels were measured. Mean \pm s.e. data from each group ( $n=5$ /group) are plotted at 8 weeks $\left({ }^{*} P<0.05\right)$. (b) Plasma serum amyloid A (SAA) levels were measured. Mean \pm s.e. data from each group ( $n=5 /$ group) are plotted at 8 weeks $\left({ }^{*} P<0.01\right)$.
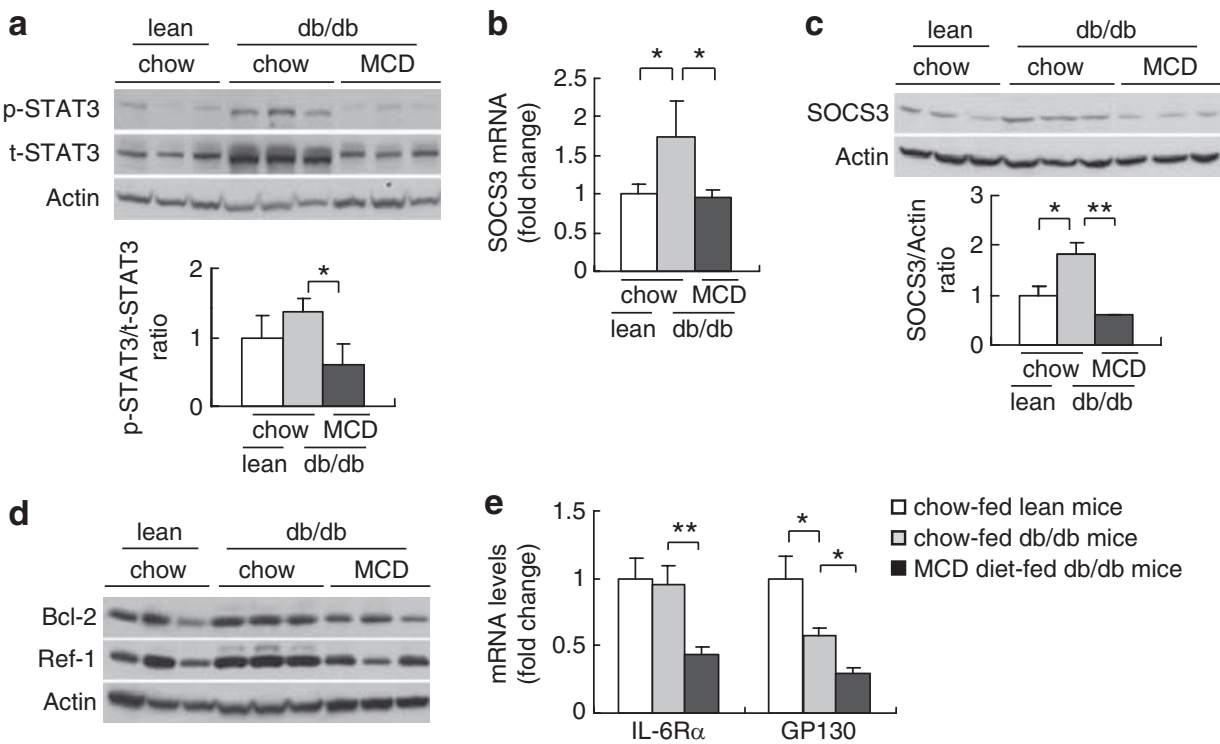

Figure 2 Hepatic interleukin-6 (IL-6)/GP130-related gene expression in lean and db/db mice. (a) Phosphorylated (p)-STAT3 and total (t)-STAT3 levels were evaluated by immunoblot analysis of livers from three mice/group after 8 weeks. To control for loading, the blot was stripped and re-probed for $\beta$-actin, a housekeeping gene product. P-STAT3/t-STAT3 ratio was also expressed as fold change of control lean mice ( $\left.{ }^{*} P<0.05\right)$. (b) mRNA levels of suppressor of cytokine signaling (SOCS3) were determined by quantitative real-time PCR analysis of total liver RNA obtained after 8 weeks. Results were normalized to glucuronidase (GUS) expression in each sample and then expressed as fold changes relative to gene expression in chow-fed control lean mice. Mean \pm s.e. data from each group ( $n=5 /$ group) $\left({ }^{*} P<0.05\right)$. (c) Protein levels of hepatic SOCS3 were assessed by immunoblot analysis. SOCS3/actin ratio was also expressed as fold change of control lean mice $\left({ }^{*} P<0.05,{ }^{*} P<0.01\right)$. (d) Protein levels of hepatic Bcl- 2 and Ref- 1 were evaluated by immunoblot analysis. (e) mRNA levels of IL- 6 receptor alpha and GP130 also were determined by quantitative real-time PCR analysis of total liver RNA obtained after 8 weeks $\left({ }^{*} P<0.05,{ }^{* *} P<0.01\right)$. 
when appropriate. Differences were considered significant when $P<0.05$.

\section{RESULTS}

An MCD Diet Elevated Plasma IL-6 Levels in Db/Db Mice

We measured plasma IL-6 levels in MCD diet-fed db/db mice and compared them with those in chow diet-fed lean and $\mathrm{db} /$ $\mathrm{db}$ mice. As a result, plasma IL-6 levels were elevated in both groups of $\mathrm{db} / \mathrm{db}$ mice and consistently higher in MCD dietfed $d b / d b$ mice than the other groups (Figure 1a). Because IL-6 is the major activator of hepatic acute phase protein expression, plasma SAA levels also were measured. As expected, plasma SAA levels in $\mathrm{db} / \mathrm{db}$ mouse groups were greatly elevated (Figure $1 \mathrm{~b}$ ). Interestingly, however, plasma SAA levels in MCD diet-fed $\mathrm{db} / \mathrm{db}$ mice were similar, or slightly lower, to those in chow-fed $\mathrm{db} / \mathrm{db}$ mice despite higher plasma IL-6 levels.

\section{An MCD Diet Suppressed IL-6 Signaling with Downregulation of Hepatic IL-6 Receptor Expression}

To evaluate hepatic IL-6/GP130 signaling, we assessed the expression of a key gene in this signaling pathway, STAT3. Hepatic STAT3 activity was slightly increased in chow-fed db/ $\mathrm{db}$ mice but, expectedly, was significantly suppressed in MCD diet-fed $\mathrm{db} / \mathrm{db}$ mice (Figure 2a). Hepatic mRNA and protein levels of suppressor of cytokine signaling (SOCS)3, which is induced by phosphorylated STAT3, were significantly decreased in MCD diet-fed $\mathrm{db} / \mathrm{db}$ mice (Figures $2 \mathrm{~b}$ and $\mathrm{c}$ ). The expression of the STAT3-related antiapoptotic and DNA repair genes, $B c l-2$ and Ref-1, also were assessed. Protein levels of $B c l-2$ and Ref-1 increased in $\mathrm{db} / \mathrm{db}$ mouse livers, but an MCD diet decreased the expression of these genes (Figure 2d). To explain this discrepancy between elevated plasma IL-6 levels and reduced hepatic STAT3 activity in MCD diet-fed $\mathrm{db} / \mathrm{db}$ mice, we analyzed mRNA levels of the IL-6 receptor alpha $(\mathrm{R} \alpha)$ and GP130. Surprisingly, although hepatic IL-6 $\mathrm{R} \alpha$ expression in chow-fed $\mathrm{db} / \mathrm{db}$ mice was similar to that in lean mice, MCD diet-fed $\mathrm{db} / \mathrm{db}$ mice expressed significantly lower amounts of IL-6 R $\alpha$ (Figure 2e). An MCD diet also led to decreased hepatic mRNA levels of GP130 in $\mathrm{db} / \mathrm{db}$ mice (Figure 2e).

\section{Treatment with MR16-1 Successfully Inhibited IL-6 Signaling}

An MCD diet was found to increase plasma IL-6 levels but suppress hepatic STAT3 signaling in $\mathrm{db} / \mathrm{db}$ mice. Because earlier studies and our previous experiments had demonstrated that the half life of MR16-1 is about 3 days, and twice
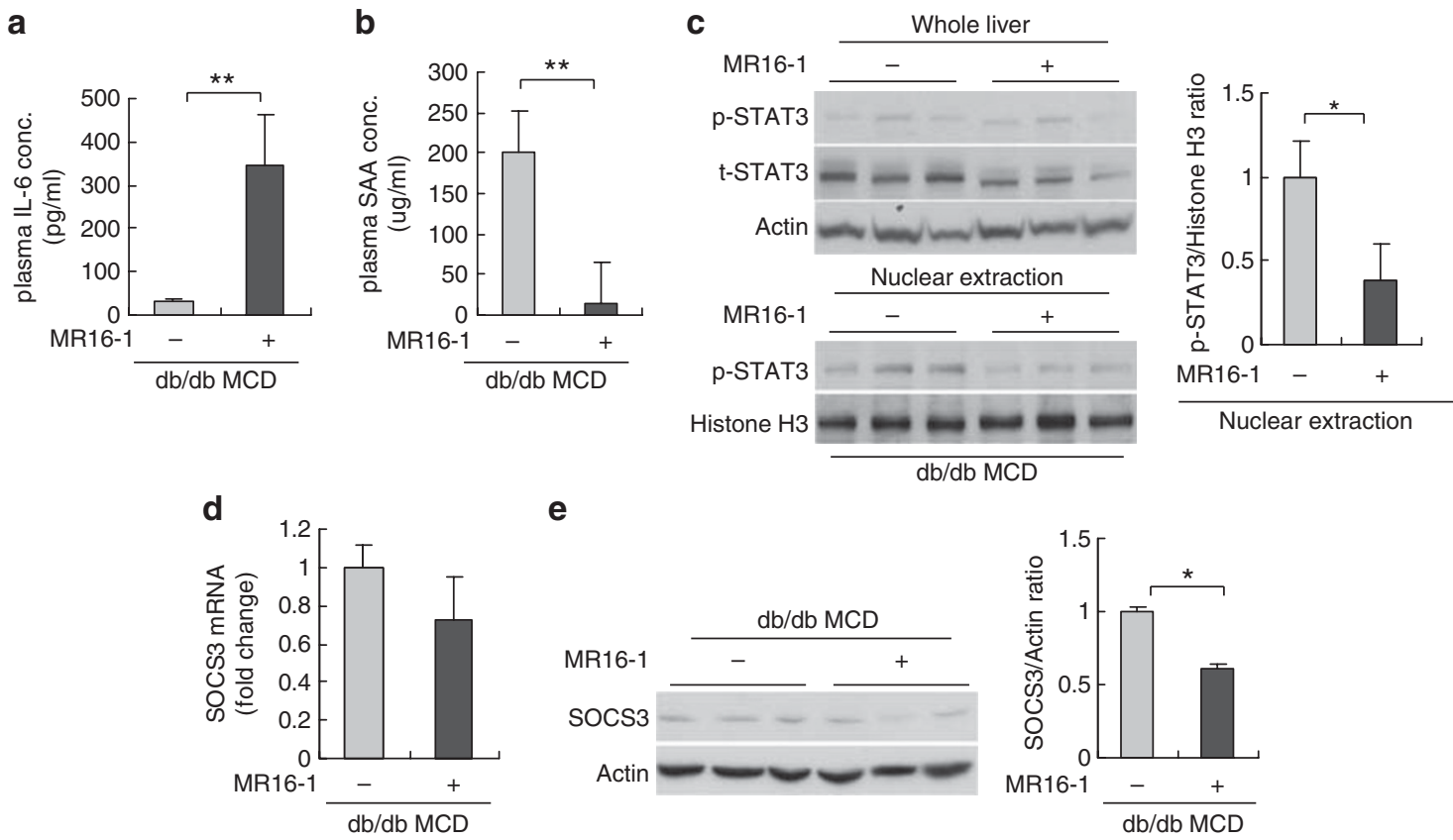

e
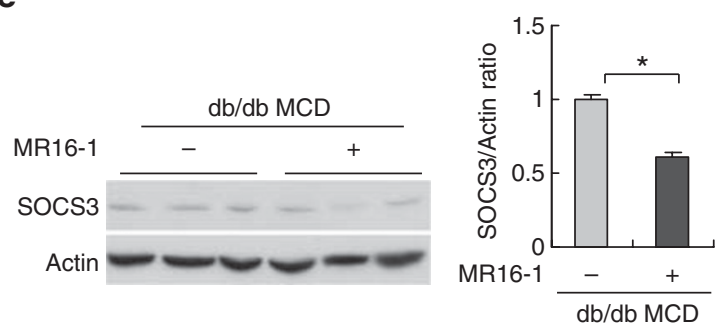

Figure 3 The effect of MR16-1 treatment on plasma interleukin-6 (IL-6) levels and hepatic IL-6/GP130-related gene expression in murine methionine choline deficient (MCD) diet-fed db/db mice. (a) Plasma IL-6 levels were measured after MR16-1 treatment. Mean \pm s.e. data from each MCD diet-fed group ( $n=5$ /group) are plotted at 8 weeks $(* * P<0.01)$. (b) Plasma serum amyloid A (SAA) levels also were measured. Mean \pm s.e. data from each MCD dietfed group ( $n=5$ /group) are plotted at 8 weeks $(* * P<0.01)$. (c) P-STAT3 levels were evaluated by immunoblot analysis of whole livers or nuclear extraction from three mice/group after 8 weeks of MR16-1 treatment. To control for loading, the blot was stripped and re-probed for actin or histone H3. Nuclear p-STAT3/histone H3 ratio was also expressed as fold change of control lgG-treated mice $\left({ }^{*} P<0.05\right)$. (d) Hepatic mRNA levels of suppressor of cytokine signaling (SOCS3) were determined by quantitative real-time PCR analysis after 8 weeks of treatment. Results were normalized to glucuronidase (GUS) expression and then expressed as fold changes relative to gene expression in MCD diet-fed control db/db mice. Mean \pm s.e. data from each MCD diet-fed group ( $n=5$ /group). (e) Protein levels of hepatic SOCS3 expression were assessed by immunoblot analysis. SOCS3/actin ratio was also expressed as fold change of MCD diet-fed control $\mathrm{db} / \mathrm{db}$ mice $\left({ }^{*} P<0.05\right)$. 
a

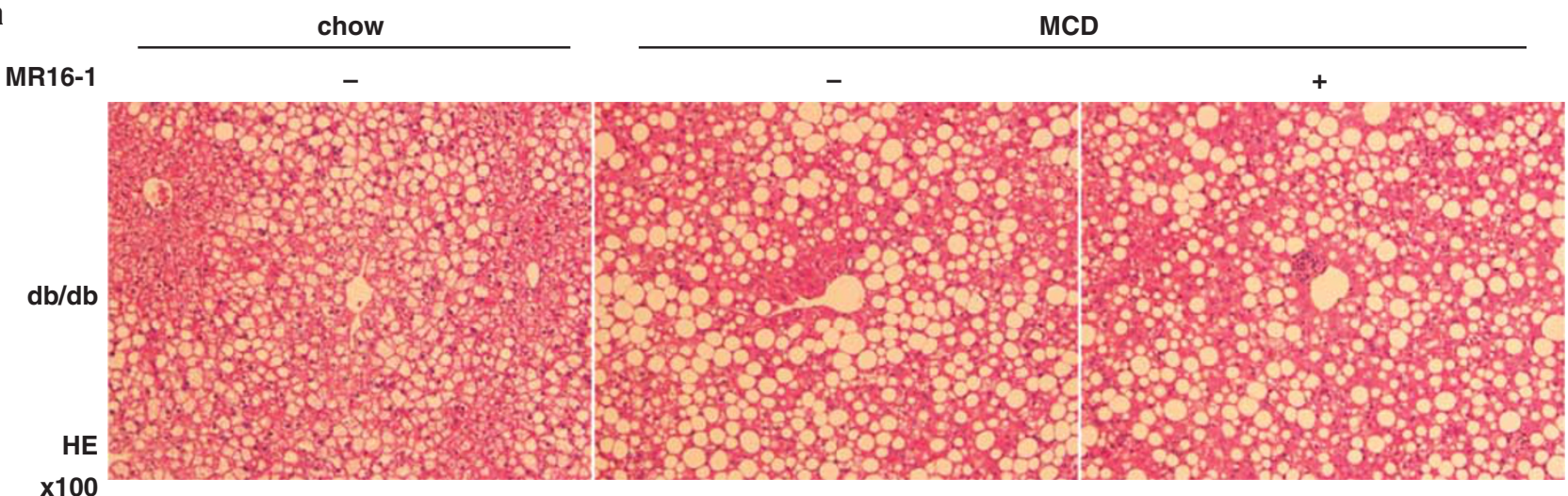

b

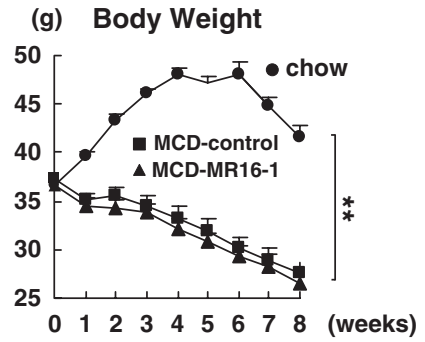

C

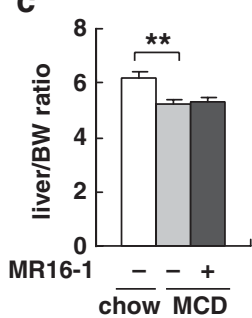

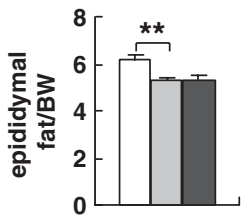

MR16-1 $\frac{-}{\cos }$ d

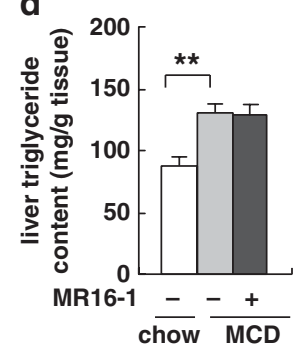

e

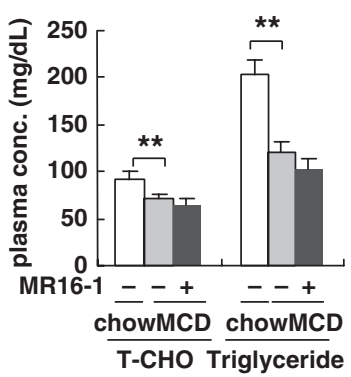

$(\mu \mathrm{EQ} / \mathrm{L})$

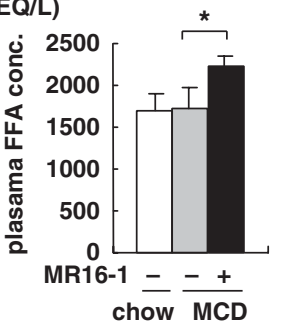

f FATP1

FATP2

FATP5

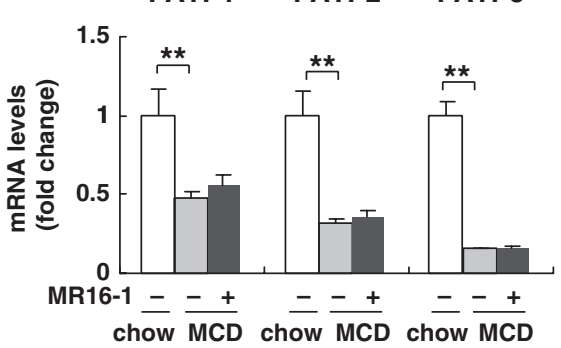

Figure 4 Liver histology, liver/BW ratio, liver triglyceride content and plasma total-cholesterol, triglyceride and free fatty acid (FFA) levels in $\mathrm{db} / \mathrm{db}$ mice. (a) Hematoxylin and eosin staining of liver sections from representative mice from each treatment group. (b) Body weight changes during 8 week-MR16-1 treatment are plotted. Mean \pm s.e. data from each group are plotted at each week (**P<0.01). (c) Liver/body weight (BW) and epididymal fat/BW ratio were assessed at the end of treatment. Mean \pm s.e. data from each group are plotted at 8 weeks $(* * P<0.01)$. (d) Liver triglycerides also were measured. Results are expressed per gram tissue. Mean \pm s.e. data from each group are plotted at 8 weeks $\left({ }^{* * P}<0.01\right)$. (e) Plasma total-cholesterol (T-CHO), triglyceride and FFA levels were determined in each group ( $n=5 /$ group) at the end of the 8 week treatment period. Data are presented as Mean \pm s.e. $\left({ }^{*} P<0.05,{ }^{*} P<0.01\right)$. (f) mRNA levels of hepatic FATP1, 2 and 5 were determined by quantitative real-time PCR analysis after 8 weeks of treatment. Results were normalized to glucuronidase (GUS) expression and then expressed as fold changes relative to gene expression in chow-fed control $\mathrm{db} / \mathrm{db}$ mice. Mean \pm s.e. data from each group ( $n=5 /$ group) $\left({ }^{*} p<0.01\right)$.

weekly intraperitoneal injections of $15 \mathrm{mg} / \mathrm{kg}$ MR16-1 suppresses the IL6/GP130 signaling pathway effectively in other murine models, as well as in chow-fed $\mathrm{db} / \mathrm{db}$ mice and MCD diet-fed lean mice, (Supplementary Figures 1 and $2 b-\mathrm{d}^{17,23}$ ), we used $15 \mathrm{mg} / \mathrm{kg}$ MR16-1 to block the IL-6/GP130 signaling pathway and determined whether or not this blockade ameliorated MCD diet-induced NASH.

First, we measured plasma IL- 6 and SAA concentrations after MR16-1 treatment. Expectedly, plasma IL-6 levels were greatly elevated but, in contrast, plasma SAA levels were suppressed by MR16-1 treatment in MCD diet-fed $\mathrm{db} / \mathrm{db}$ mice $^{24}$ (Figures $3 \mathrm{a}$ and $\mathrm{b}$ ). These observations suggested that MR16-1 treatment blocked the IL-6 receptor successfully. Consequently, in MCD diet-fed $\mathrm{db} / \mathrm{db}$ mice, the translocation of phosphorylated STAT3 into the nuclei was significantly decreased by this treatment, and mRNA levels of hepatic SOCS3 expression also tended to decrease (Figures 3c and d). We also confirmed that the level of SOCS3 protein was decreased by MR16-1 treatment (Figure 3e).

\section{Neutralizing the IL-6 Receptor had Little Effect on Hepatic Steatosis Despite Increased Plasma FFA Levels}

In obesity, the major mechanism driving the accumulation of hepatic triglyceride is increased delivery of FFA from 
peripheral adipose depots to the liver. Hepatic lipid disposal via mitochondrial beta oxidation and lipoprotein export are central mechanisms for removing potentially toxic FFA. In $\mathrm{db} / \mathrm{db}$ mice, in which obesity drives increased delivery of FFA to the liver, it has been demonstrated that an MCD diet exacerbates steatosis dramatically. ${ }^{14-16}$

We assessed hepatic steatosis by H\&E staining, liver/body weight (BW) ratio, epididymal fat/BW ratio and liver triglyceride content at the end of 8 weeks of treatment. An MCD diet induced further intra-hepatic lipid accumulation in $\mathrm{db} / \mathrm{db}$ mice but MR16-1 treatment had no effect on hepatic steatosis (Figure 4a). Body weight changes, liver/BW ratio, epididymal fat/BW ratio and liver triglyceride content were similar in MCD diet-fed $\mathrm{db} / \mathrm{db}$ mice with and without MR16-1 treatment (Figure 4b-d). Plasma T-CHO and triglyceride levels also were similar in the two groups but plasma FFA levels were significantly higher in $\mathrm{db} / \mathrm{db}$ mice treated with MR16-1 (Figure 4e). To investigate why plasma FFA levels were increased by MR16-1 treatment, we assessed mRNA levels of hepatic FATP1, 2 and 5. An MCD diet decreased hepatic FATPs expression in $\mathrm{db} / \mathrm{db}$ mice but MR16-1 treatment had no effect on this (Figure $4 \mathrm{f}$ ).
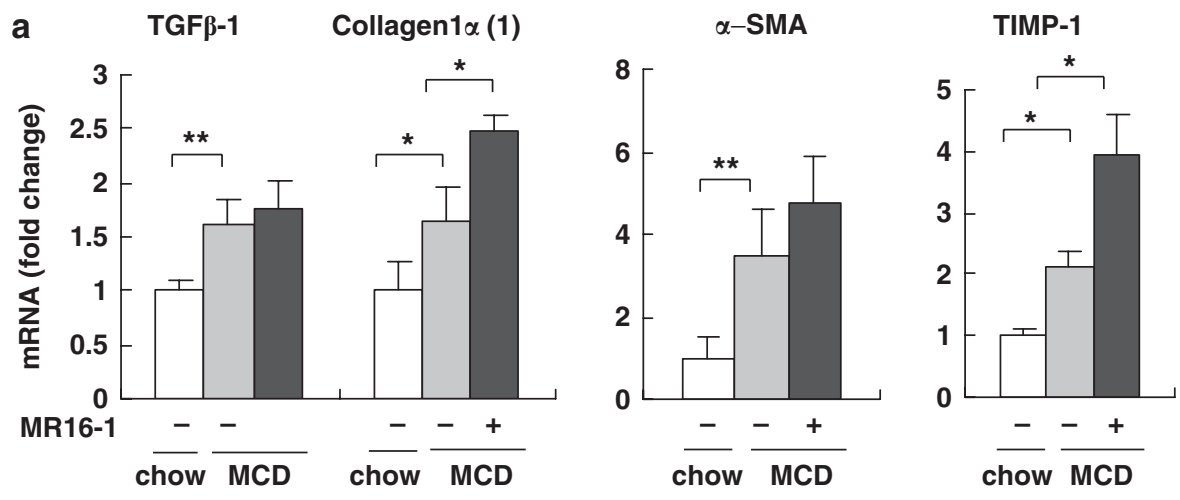

b

MCD

C
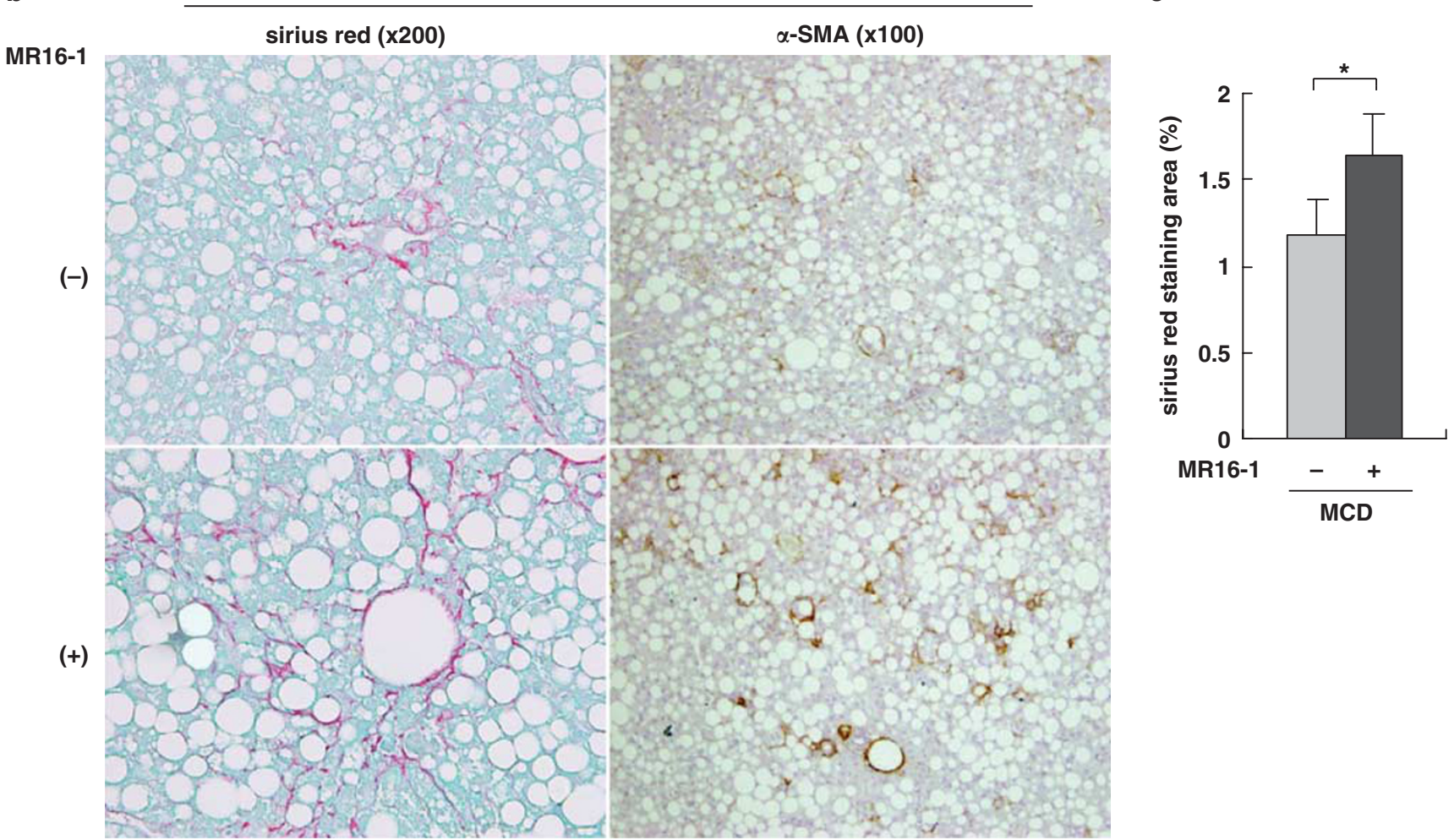

Figure 5 Fibrosis markers in $\mathrm{db} / \mathrm{db}$ mice. (a) mRNA levels of TGF $\beta-1$, collagen, $\alpha$-smooth muscle actin ( $\alpha$-SMA) and tissue inhibitor of metalloproteinases (TIMP-1) were determined by quantitative real-time PCR analysis after 8 weeks of treatment. Results were normalized to glucuronidase (GUS) expression. Mean \pm s.e. data from each sample are displayed as fold changes relative to chow-fed control db/db mice $\left({ }^{*} P<0.05,{ }^{* * P}<0.01\right)$. (b) Liver sections from all mice were stained with Sirius Red and $\alpha$-SMA antibody after 8 weeks of treatment. Photomicrographs from representative mice are shown. (c) Morphometric analysis of Sirius Red-stained sections from each murine methionine choline deficient (MCD) diet-fed group ( $n=5 / \mathrm{group}$ ) at 8 weeks. Results are expressed as percentage of section staining $(+)$ for Sirius Red $\left({ }^{*} P<0.05\right)$. 


\section{Neutralizing the IL-6 Receptor Exacerbated MCD Diet-Induced Liver Fibrosis}

To evaluate the effect of MR16-1 treatment on liver fibrosis, mRNA levels of various markers of fibrosis were compared in the three groups of mice. Hepatic expressions of TGF $\beta-1$, collagen, $\alpha$-SMA and tissue inhibitor of metalloproteinases (TIMP)- 1 were significantly increased in $\mathrm{db} / \mathrm{db}$ mice fed with an MCD diet. Furthermore, treatment with MR16-1enhanced MCD diet-induced hepatic increases in collagen and TIMP-1 mRNA expression significantly, whereas enhanced expression of $\alpha$-SMA was modest and the expression of TGF $\beta$-1 was unaltered (Figure $5 \mathrm{a}$ ). To assess further the effects of an MCD diet and MR16-1 treatment on liver fibrosis, Sirius red staining and $\alpha$-SMA immunohistochemical analysis were performed. As predicted from the results for the markers of hepatic fibrosis, MCD diet-fed $\mathrm{db} / \mathrm{db}$ mice treated with MR16-1 had the greatest area of Sirius red-stained fibrils, demonstrated by liver morphometry, and the greatest number of $\alpha$-SMA-positive cells among the three groups of mice. (Figures $5 b$ and $c$ ).

\section{Neutralizing the IL-6 Receptor Exacerbated MCD Diet-Induced Liver Injury}

We compared injury-related parameters among the three groups of mice. An MCD diet increased TNF- $\alpha$ mRNA levels in the livers of $\mathrm{db} / \mathrm{db}$ mice (Figure 6a). However, treatment with MR16-1 for 8 weeks had no additional effect. Consistent with the evidence that an MCD diet-increased hepatic TNF- $\alpha$ expression, control IgG-treated $\mathrm{db} / \mathrm{db}$ mice that were fed MCD diets exhibited twofold higher plasma AST, and threefold higher ALT, values than $\mathrm{db} / \mathrm{db}$ controls (Figure $6 \mathrm{~b}$ ). Interestingly, plasma AST and ALT values were highest in MCD diet-fed mice that were treated with MR16-1, suggesting that MR16-1 treatment may exacerbate liver injury. To confirm this finding, liver sections also were evaluated for lobular inflammation. The lobular inflammatory grade tended to be higher in MCD diet-fed mice than that in chow-fed controls. MR16-1 treatment for 8 weeks exacerbated MCD diet-induced lobular inflammation slightly, but not significantly. (Figure $6 c, P=0.076$ ).

\section{Neutralizing the IL-6 Receptor Increased Lipid Peroxidation/Oxidant Stress and Hepatic Apoptosis}

To determine the mechanism of exacerbation of liver damage and fibrosis, caused by blocking the IL- 6 receptor in this model, we examined the markers of lipotoxicity and hepatic apoptosis at the end of 8 weeks of treatment. $\mathrm{Db} / \mathrm{db}$ mice that were treated with MR16-1 had significantly greater hepatic accumulation of HNE and demonstrated increases in thiobarbituric acid-reactive (TBAR) substance level (Figures $7 \mathrm{a}$ and b). Furthermore, the levels of the STAT3-related antiapoptotic protein, $\mathrm{Bcl}-2$, and the DNA repair and Racdependent NADPH oxidase inhibitor protein, Ref-1, also were significantly decreased in MR16-1-treated mouse livers (Figure 7c). Consistent with these findings, the percentage of TUNEL-positive hepatocytes was higher in MR16-1-treated $\mathrm{db} / \mathrm{db}$ mice than $\mathrm{db} / \mathrm{db}$ controls (Figure $7 \mathrm{~d}$ ). Thus, increased lipotoxicity and hepatic apoptosis resulting from inhibition of STAT3-related hepato-protective gene expression by MR16-1 treatment may be the cause of exacerbated liver damage in this model.

\section{Neutralizing the IL-6 Receptor for 12 Weeks Further Exacerbated Liver Fibrosis and Injury, and Enhanced Hepatic Apoptosis}

Because the additional effect of MR16-1 treatment on hepatic injury and fibrosis was not clearly demonstrated in MCDdiet fed $\mathrm{db} / \mathrm{db}$ mice after 8 weeks of treatment, prolonged treatment with MR16-1 was carried out for 12 weeks. As expected, this treatment resulted in significantly increased plasma ALT values (Figure 8a), hepatic inflammatory score and TNF- $\alpha$ expression (Figures $8 \mathrm{~b}$ and $\mathrm{c}$ ). Interestingly, significantly increased mRNA levels of TGF $\beta$ - 1 and $\alpha$-SMA also were noted, in addition to the increase in collagen and TIMP-1 mRNA observed after 8-weeks treatment (Figure 8c). An increase in the Sirius red-stained area (Figure 8d), decreased expression of Bcl-2 and Ref-1 (Figure 8e), and an increased number of TUNEL-positive hepatocytes also were observed (Figure 8f).
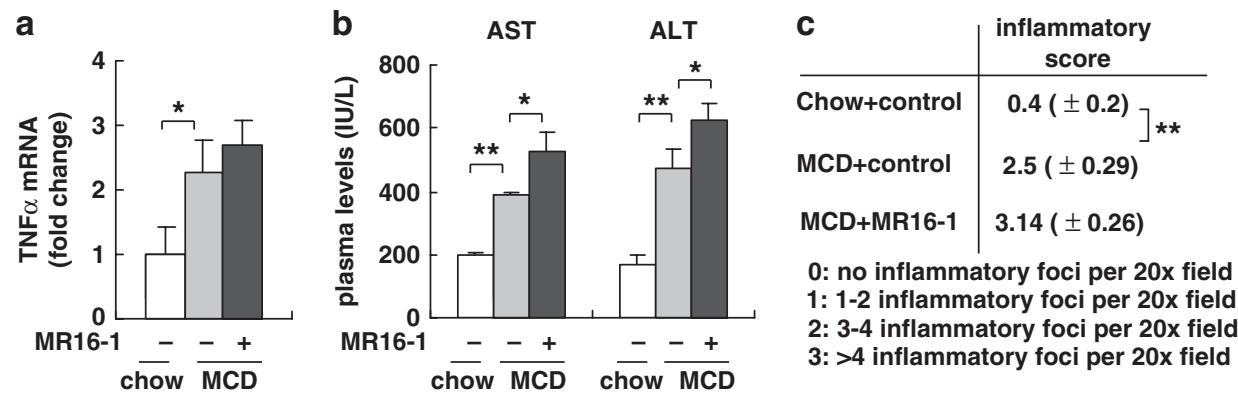

Figure 6 Injury-related parameters in $\mathrm{db} / \mathrm{db}$ mice at the end of 8 weeks. (a) The mRNA level of tumor necrosis factor-alpha (TNF- $\alpha$ ) was evaluated by quantitative real-time PCR analysis from each group ( $n=5 /$ group) at 8 weeks. Results were normalized to glucuronidase (GUS) expression. Mean \pm s.e. data are displayed as fold changes relative to chow-fed control db/db mice ( $\left.{ }^{\star} P<0.05\right)$. (b) Plasma aspartate aminotransferase (AST) and alanine aminotransferase (ALT) levels were measured after 8 weeks of treatment. Mean \pm s.e. results from each group $\left(n=5 /\right.$ group) $\left({ }^{\star} P<0.05,{ }^{*} P<0.01\right)$. (c) The number of inflammatory foci per $200 \times$ field was counted on sections from each mouse. Mean \pm s.e. data from each group ( $n=5 /$ group) are displayed ( $* *<0.01$ ). 
a
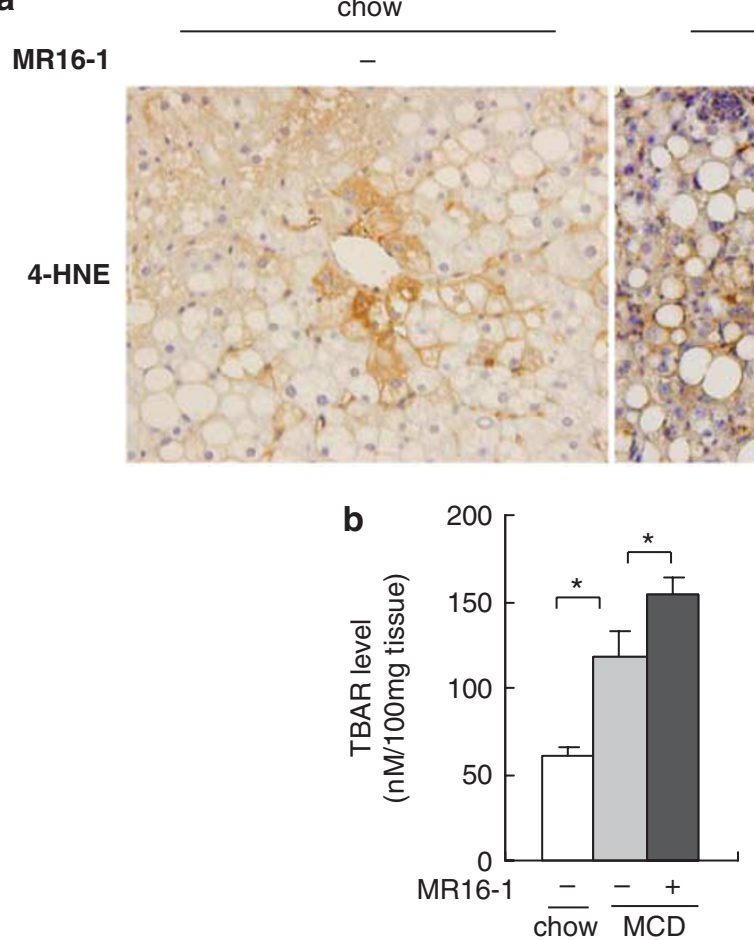

MCD

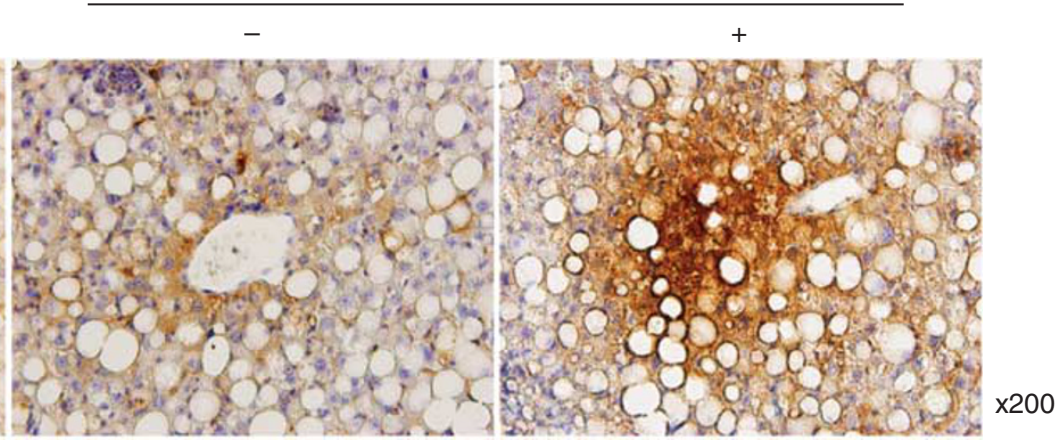

C

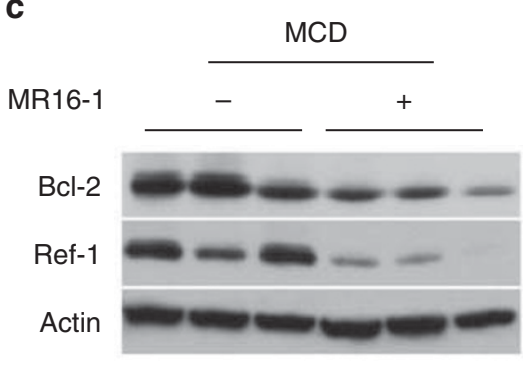

d

MCD

MR16-1

$(-)$

$(+)$
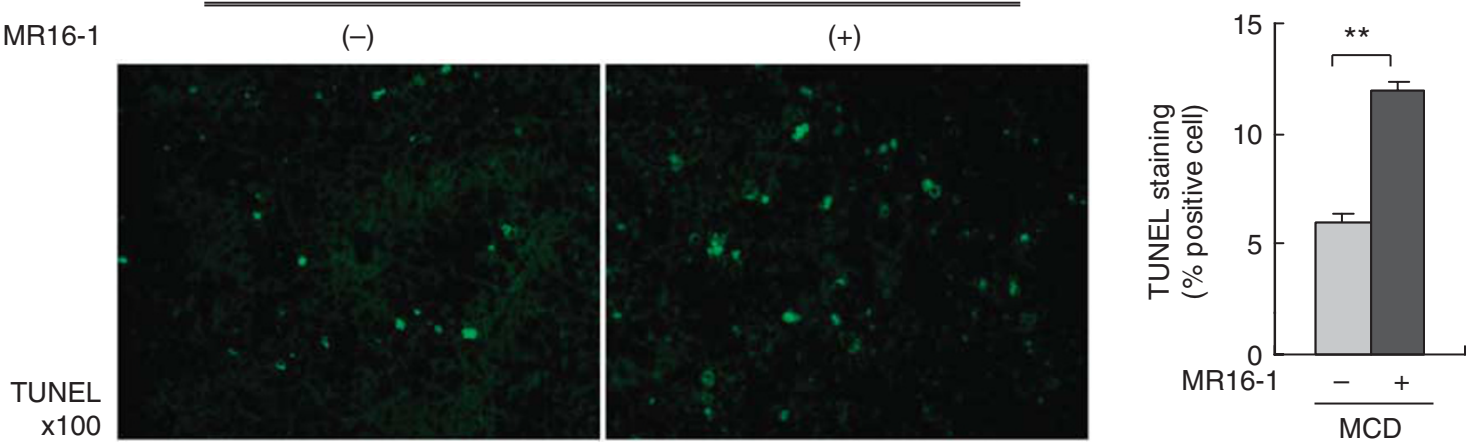

Figure 7 Parameters of lipotoxicity, oxidant stress and apoptosis in db/db livers. (a) 4-hydroxy-2-nonenal (4-HNE) was evaluated by immunohistochemistry in liver samples from chow-fed control and murine methionine choline deficient (MCD) diet-fed db/db mice at the end of the 8-week treatment period. Photomicrographs from representative mice are shown. (b) Tissue thiobarbituric acid-reactive (TBAR) levels were evaluated at 8 weeks. Results were normalized per $100 \mathrm{mg}$ tissue. Mean \pm s.e. data from controls $(n=5)$ and each MCD diet-fed group ( $n=5 /$ group) $\left({ }^{*} P<0.05\right)$. (c) Hepatic Bcl-2 and Ref- 1 levels were evaluated by immunoblot analysis of livers from three mice/group after 8 weeks. (d) Apoptosis of hepatocytes was evaluated by TUNEL staining of liver sections after 8 weeks of treatment. Photomicrographs from representative mice are shown. TUNEL-positive hepatocytes were counted in three randomly selected fields/section ( $\times 100$ magnification) from each MCD diet-fed group ( $n=5 /$ group) at 8 weeks. Results are expressed as percentage of nuclei staining $(+)$ for TUNEL $(* * P<0.01)$.

\section{DISCUSSION}

Oxidative stress, lymphocyte activation and cytokine release are candidate elements of the pathogenic transition from simple steatosis to steatohepatitis. ${ }^{25}$ In this study, plasma IL-6 levels were elevated in both chow- and MCD diet-fed $\mathrm{db} / \mathrm{db}$ mice compared with lean mice (Figure 1). The expression of hepatic IL-6/GP130-related molecules also was upregulated in chow-fed $\mathrm{db} / \mathrm{db}$ mice (Figure 2). However, an MCD diet induced the loss of STAT3 phosphorylation and hepatic IL-6/ GP130-related gene expression, despite the greater elevation of plasma IL-6 levels in $\mathrm{db} / \mathrm{db}$ mice. On this basis, we hypothe- sized that the MCD diet-induced 'hepatic IL- 6 resistance' observed in $\mathrm{db} / \mathrm{db}$ mice may be attributable to impaired hepatic IL-6 receptor and GP130 mRNA expression, because a previous report showed that treatment with IL-6/soluble IL-6 receptor fusion protein stimulated IL-6-mediated signaling pathway. ${ }^{26}$ As shown in Figure 2e, hepatic mRNA expression of the IL-6 receptor and GP130 was confirmed to be significantly downregulated in MCD diet-fed $\mathrm{db} / \mathrm{db}$ mice, which did not contradict the finding of decreased hepatic STAT3 levels.

Initially, we hypothesized that continuous IL-6 stimulation might induce liver injury and fibrosis, and neutralizing the 


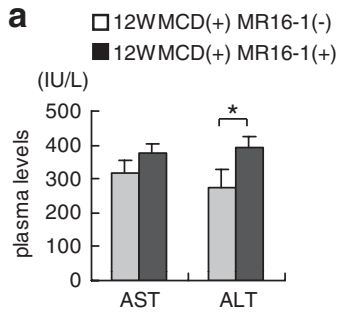

b

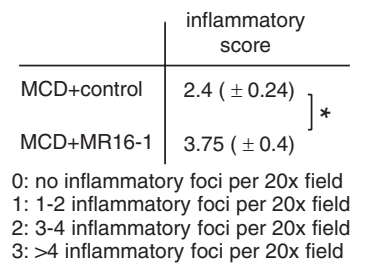

C

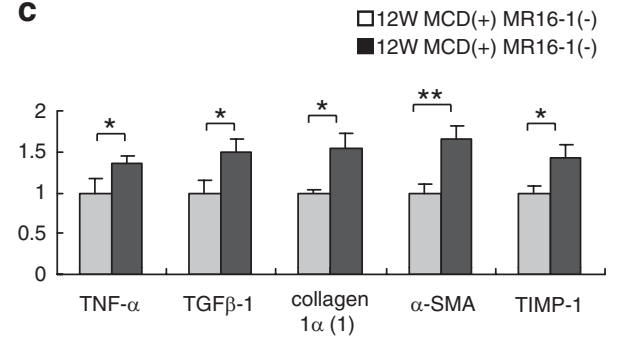

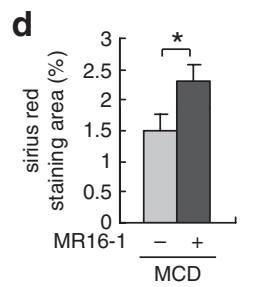
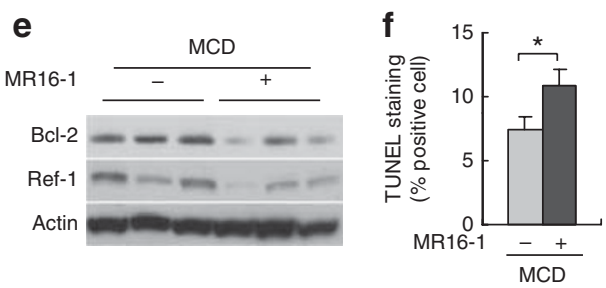

Figure 8 Fibrosis markers and injury- and hepatic apoptosis-related parameters in $\mathrm{db} / \mathrm{db}$ mice after 12 weeks. (a) Plasma aspartate aminotransferase (AST) and alanine aminotransferase (ALT) levels also were measured in each murine methionine choline deficient (MCD) diet-fed db/db mouse group after 12 weeks of treatment. Mean \pm s.e. results from each group ( $n=5 /$ group) $(* P<0.05)$. (b) The number of inflammatory foci per $200 \times$ field was counted on sections from each mouse. Mean \pm s.e. data from each group $\left(n=5 /\right.$ group) are displayed $\left({ }^{*}>0.05\right)$. (c) The mRNA levels of tumor necrosis factor-alpha (TNF- $\alpha$ ), TGF $\beta-1$, collagen, $\alpha$-smooth muscle actin ( $\alpha$-SMA) and tissue inhibitor of metalloproteinases (TIMP-1) also were evaluated by quantitative real-time PCR analysis from each MCD diet-fed $\mathrm{db} / \mathrm{db}$ mouse group at 12 weeks. Results were normalized to glucuronidase (GUS) expression and then expressed as fold changes relative to gene expression in MCD diet-fed control db/db mice. Mean \pm s.e. data from each group $(n=5 / \mathrm{group})\left({ }^{*} P<0.05\right.$, $\left.{ }^{*} P<0.01\right)$. (d) Morphometric analysis of Sirius Red-stained sections from each MCD diet-fed group ( $\left.n=5 / g r o u p\right)$ at 12 weeks. Results are expressed as percentage of section staining $(+)$ for Sirius Red $\left({ }^{*} P<0.05\right)$. (e) Hepatic Bcl-2 and Ref- 1 levels were evaluated by immunoblot analysis of livers from three mice/group after 12 weeks. (f) Apoptosis of hepatocytes was evaluated by TUNEL staining of liver sections after 12 weeks of treatment. TUNEL-positive hepatocytes were counted in three randomly selected fields/section ( $\times 100$ magnification) from each MCD diet-fed group ( $n=5 / g r o u p)$ at 12 weeks. Results are expressed as percentage of nuclei staining $(+)$ for TUNEL $\left({ }^{*} P<0.05\right)$.

IL-6 receptor by treatment with MR16-1 would attenuate liver injury and prevent the development of NASH in MCD diet-fed $\mathrm{db} / \mathrm{db}$ mice, as in wild-type mice, because previous reports showed that long-term IL-6 exposure induced SOCS3 expression, caused insulin resistance and exacerbated liver injury. ${ }^{27-30}$ Expectedly, we found that an MCD diet induced severe NASH in $\mathrm{db} / \mathrm{db}$ mice. Unexpectedly, however, this diet induced IL-6 resistance. The effect of this IL-6 resistance is obvious in $\mathrm{db} / \mathrm{db}$ mice because these mice lack $\mathrm{Ob}-\mathrm{Rb}$, which is required for leptin-induced phosphorylation of STAT3 at Tyr 705 (see ref. 31,32). In this study, we used MR16-1 and found that this treatment had little effect on hepatic steatosis but induced greater liver injury and fibrosis in MCD diettreated $\mathrm{db} / \mathrm{db}$ mice, compared with control treatment. When MR16-1 treatment blocked IL-6 signaling in MCD diet-fed mice seriously, this blocking effect would have been considerable and enhanced MCD diet-induced liver damage. These observations showed that IL-6-induced STAT3 phosphorylation has a central role in inhibiting the development of MCD diet-induced NASH in $\mathrm{db} / \mathrm{db}$ mice.

We have revealed recently that MR16-1 treatment improved liver injury in wild-type mice fed with an MCD diet (Supplementary Figures 2F, G, H, I). Nevertheless, in this NASH model, IL-6 had a protective role against the development of NASH. Blocking IL-6 signaling by MR16-1 in MCD diet-fed $\mathrm{db} / \mathrm{db}$ mice, which have impaired leptinmediated IL-6 signaling, severely suppressed STAT3 activation and STAT3-mediated expression of antiapoptotic and
DNA repair genes (Figures $3 c-e, 7 c$ and $8 \mathrm{e}$ ). This also enhanced the transcription of fibrosis-related genes (Figures $5 \mathrm{a}$ and $8 \mathrm{c}$ ) and worsened hepatic injury (Figures $6 \mathrm{~b}$ and $\mathrm{c}, 8 \mathrm{a}$ and $8 \mathrm{~b}$ ). These differing observations between wild type and $\mathrm{db} / \mathrm{db}$ mice in two NASH models indicate a paradoxical role for IL-6 in the development of chronic inflammation and the promotion of hepatocyte proliferation. We speculate that, although an excess of IL-6 may exert an effect as a mediator of inflammation in human and mouse NASH, in some experimental models with severely suppressed IL-6-STAT3 signaling, such as $\mathrm{STAT}^{-1-}$ or GP130 $0^{-1-}$ mice, IL-6 may have a hepato-protective role against various types of liver injury, including steatohepatitis, as we have demonstrated in this study. ${ }^{33,34}$ We found here that MR16-1 treatment did not exacerbate hepatic steatosis (Figure 4a-d) and the expression of lipogenic genes was not altered (data not shown), despite inhibited IL-6 signaling. However, although MR16-1 treatment decreased plasma FFA levels with increased hepatic lipogenic fed wild-type mice (Supplementary Figure 2D, E, ${ }^{17}$ ), these were greatly increased in MCD diet-fed $\mathrm{db} / \mathrm{db}$ mice. This elevation of plasma FFA indicated that excess FFA accumulation in MCD diet-fed $\mathrm{db} / \mathrm{db}$ mouse livers might have been beyond the capacity of hepatic triglyceride synthesis, in part because the livers of $\mathrm{db} / \mathrm{db}$ mice were already severely fatty. FFA is a substrate for ROS-generating microsomal enzymes such as Cyp2E1, therefore, this compensatory FFA detoxification system would collapse, leading to the development of NASH with elevation of plasma FFA levels. 
Consequently, inhibition of IL-6/STAT3 signaling failed to decrease ROS generation. This may be one mechanism of the increased expression of alpha smooth muscle actin, collagen and TGF beta TGF beta in this model. Impaired IL-6/STAT3 signaling led to reduced antiapoptotic gene expression, which also caused enhanced fibrotic process in the liver.

Considering this study and other previous reports, we conclude that not only excessively upregulated, but also severely suppressed hepatic IL-6-STAT3 signaling may lead to the progression of NASH. In human NASH, IL-6-STAT3 signaling possibly may be excessively upregulated, whereas in MCD diet-fed $\mathrm{db} / \mathrm{db}$ mice this signaling was severely suppressed. Hopefully, further studies using MR16-1 in other NAFLD and NASH models will be able to reveal the effect of neutralizing the IL-6 receptor on NASH.

Supplementary Information accompanies the paper on the Laboratory Investigation website (http://www.laboratoryinvestigation.org)

\section{ACKNOWLEDGEMENT}

This study was supported by Grant-in-Aid for Scientific Research from the Japan Society for the Program of Science (Kanji Yamaguchi).

\section{DISCLOSURE/CONFLICT OF INTEREST}

The authors declared no conflict of interests.

1. Ludwig J, Viggiano TR, McGill DB, et al. Nonalcoholic steatohepatitis: mayo clinic experience with a hitherto unnamed disease. Mayo Clinic Proc 1980;55:434-438.

2. Baranova A, Schlauch $\mathrm{K}$, Elariny $\mathrm{H}$, et al. Gene expression patterns in hepatic tissue and visceral adipose tissue of patients with nonalcoholic fatty liver disease. Obes Surg 2007;17:1111-1118.

3. Jarrar MH, Baranova A, Collantes R, et al. Adipokines and cytokines in non-alcoholic fatty liver disease. Aliment Pharmacol Ther 2008;27:412-421.

4. Wieckowska A, Papouchado BG, Li Z, et al. Increased hepatic and circulating interleukin-6 levels in human nonalcoholic steatohepatitis. Am J Gastroenterol 2008;103:1372-1379.

5. Cressman DE, Greenbaum LE, DeAngelis RA, et al. Liver failure and defective hepatocyte regeneration in interleukin-6-deficient mice. Science 1996;274:1379-1383.

6. Selzner $N$, Selzner $M$, Odermatt $B$, et al. ICAM-1 triggers liver regeneration through TNF and IL- 6 release in mice. Gastroenterology 2003;124:692-700.

7. Febbraio MA. Gp130 receptor ligands as potential therapeutic targets for obesity. J Clin Invest 2007;117:841-849.

8. Inoue $\mathrm{H}$, Ogawa $\mathrm{W}$, Ozaki $\mathrm{M}$, et al. Role of STAT-3 in regulation of hepatic gluconeogenic genes and carbohydrate metabolism in vivo. Nat Med 2004;10:168-174.

9. Klein C, Wüstefeld T, Assmus U, et al. The IL-6-gp130-STAT3 pathway in hepatocytes triggers liver protection in T cell-mediated liver injury. J Clin Invest 2005;115:860-869.

10. Kovalovich K, Li W, DeAngelis R, et al. Interleukin-6 protects against Fas-mediated death by establishing a critical level of anti-apoptotic hepatic proteins FLIP, BCl-2, and Bcl-xl. J Biol Chem 2001;276: 26605-26613.

11. Sun $Z$, Klein AS, Radaeva $S$, et al. In vitro interleukin-6 treatment prevents mortality associated with fatty liver transplants in rats. Gastroenterology 2003;125:202-215.

12. Jin X, Zhang Z, Beer-Stolz D, et al. Interleukin-6 inhibits oxidative injury and necrosis after extreme liver resection. Hepatology 2007; $46: 802-812$.
13. Chen $\mathrm{H}$, Charlat $\mathrm{O}$, Tartaglia LA, et al. Evidence that diabetes gene encodes the leptin receptor: identification of a mutation in the leptin receptor gene in db/db mice. Cell 1996;84:491-495.

14. Sahai A, Malladi P, Pan X, et al. Obese and diabetic $\mathrm{db} / \mathrm{db}$ mice develop marked liver fibrosis in a model of nonalcoholic steatohepatitis: role of short-form leptin receptors and osteopontin. Am J Physiol Gastrointest Liver Physiol 2004;287:G1035-G1043.

15. Rinella ME, Elias MS, Smolak RR, et al. Mechanisms of hepatic steatosis in mice fed a lipogenic methionine choline-deficient diet. J Lipid Res 2008;49:1068-1076.

16. Larter CZ, Yeh MM, Haigh WG, et al. Hepatic free fatty acids accumulate in experimental steatohepatitis: role of adaptive pathways. J Hepatol 2008;48:638-647.

17. Yamaguchi $\mathrm{K}$, Itoh $\mathrm{Y}$, Yokomizo $\mathrm{C}$, et al. Blockade of interleukin-6 signaling enhances hepatic steatosis but improves liver injury in methionine choline-deficient diet-fed mice. Lab Invest 2010;90: 1169-1178.

18. Okazaki $\mathrm{M}$, Yamada $\mathrm{Y}$, Nishimoto $\mathrm{N}$, et al. Characterization of antimouse interleukin-6 receptor antibody. Immunol Lett 2002;84: 231-240.

19. Izumi-Nagai K, Nagai N, Ozawa Y, et al. Interleukin-6 receptor-mediated activation of signal transducer and activator of transcription-3 (STAT3) promotes choroidal neovascularization. Am J Pathol 2007;170:2149-2158.

20. Yamaguchi K, Yang L, McCall S, et al. Inhibiting triglyceride synthesis improves hepatic steatosis but exacerbates liver damage and fibrosis in obese mice with nonalcoholic steatohepatitis. Hepatology 2007;45:1366-1374.

21. Livak KJ, Schmittgen TD. Analysis of relative gene expression data using real-time quantitative PCR and the 2(-Delta Delta $\mathrm{C}(\mathrm{T})$ ) Method. Methods 2001;25:402-408.

22. Schmittgen TD, Livak KJ. Analyzing real-time $P C R$ data by the comparative $C(T)$ method. Nat Protoc 2008;3:1101-1108.

23. Okada S, Nakamura M, Mikami $Y$, et al. Blockade of interleukin-6 receptor suppresses reactive astrogliosis and ameliorates functional recovery in experimental spinal cord injury. J Neurosci Res 2004;76:265-276.

24. Uchiyama $Y$, Yoshida $H$, Koike $N$, et al. Anti-IL-6 receptor antibody increases blood IL- 6 level via the blockade of IL- 6 clearance, but not via the induction of IL-6 production. Int Immunopharmacol 2008;8: 1595-1601.

25. Day CP, James OF. Steatohepatitis: a tale of two 'hit'? Gastroenterology 1998;114:842-845.

26. Peters $M$, Blinn $G$, Jostock $T$, et al. Combined interleukin 6 and soluble interleukin 6 receptor accelerates murine liver regeneration. Gastroenterology 2000;119:1663-1671.

27. Jin X, Zimmers TA, Perez EA, et al. Paradoxical effects of short- and long-term interleukin- 6 exposure on liver injury and repair. Hepatology 2006;43:474-484.

28. Rotter Sopasakis V, Larsson BM, Johansson A, et al. Short-term infusion of interleukin-6 does not induce insulin resistance in vivo or impair insulin signalling in rats. Diabetologia 2004;47:1879-1887.

29. Senn JJ, Klover PJ, Nowak IA, et al. Suppressor of cytokine signaling-3, a potential mediator of interleukin-6-dependent insulin resistance in hepatocytes. J Biol Chem 2003;278:13740-13746.

30. Ueki K, Kondo T, Tseng $\mathrm{YH}$, et al. Central role of suppressors of cytokine signaling proteins in hepatic steatosis, insulin resistance, and the metabolic syndrome in the mouse. Proc Natl Acad Sci 2004;101: 10422-10427.

31. Bates SH, Stearns WH, Dundon TA, et al. STAT3 signalling is required for leptin regulation of energy balance but not reproduction. Nature 2003;421:856-859.

32. Banks AS, Davis SM, Bates SH, et al. Activation of downstream signals by the long form of the leptin receptor. J Biol Chem 2000;275: 14563-14572.

33. Kroy DC, Beraza N, Tschaharganeh DF, et al. Lack of interleukin-6/ glycoprotein 130/signal transducers and activators of transcription-3 signaling in hepatocytes predisposes to liver steatosis and injury in mice. Hepatology 2010;51:463-473. 